\title{
Knowledge, attitude, and practices towards COVID-19 among general population in northern India
}

\author{
Amiya*, Jyoti Kaushal
}

Department of Pharmacology, Pt. B. D. Sharma PGIMS, Rohtak, Haryana, India

Received: 12 January 2021

Revised: 09 February 2021

Accepted: 10 February 2021

*Correspondence:

Dr. Amiya,

Email: dramiyapgims@gmail.com

Copyright: (C) the author(s), publisher and licensee Medip Academy. This is an open-access article distributed under the terms of the Creative Commons Attribution Non-Commercial License, which permits unrestricted non-commercial use, distribution, and reproduction in any medium, provided the original work is properly cited.

\begin{abstract}
Background: Coronavirus disease (COVID-19) is a respiratory disease caused by a newly discovered coronavirus. The disease is highly infectious, it causes severe acute respiratory syndrome (SARS CoV-2). In India, there are more than 2.5 lac active COVID19 cases and case fatality rate of COVID-19 is 1.45\% as per Ministry of Health and Family Welfare (MoHFW) on 1 January 2021. To guarantee the final success, people's adherence to preventive measures is necessary.

Methods: Survey was conducted to investigate the knowledge, attitude and practices towards COVID-19 among general population in northern India. Data was collected telephonically, using a structured questionnaire from 100 participants. Total 30 questions were included in questionnaire.

Results: Regarding mode of spread, $82 \%$ believed in respiratory droplets (coughing, sneezing), $76 \%$ in touching and shaking hand with infected person, $37 \%$ in use of objects used by infected person. Regarding symptoms of the disease, $88 \%$ participants voted for fever, $62 \%$ for dry cough, $55 \%$ for sore throat, and $82 \%$ for difficulty in breathing. Regarding attitude, $72 \%$ had confidence that India can win the battle against COVID-19. Evaluation of prevention practices showed that $38 \%$ still visited crowded places and $22 \%$ had not worn masks in public places. Only $48 \%$ maintained 6 feet distance with others.

Conclusions: Knowledge and attitude in most of the areas were quite adequate but actual practices for preventing measures were lacking. So, more awareness programs and more such surveys regarding following the appropriate measures are need of the hour to prevent the spread of this highly communicable and deadly disease.
\end{abstract}

Keywords: COVID-19, Knowledge, Attitude, Practices

\section{INTRODUCTION}

Coronavirus disease (COVID-19) is a respiratory disease caused by a newly discovered coronavirus. It was first identified in December 2019 in Wuhan, China. The disease is highly infectious and has spread globally now. The WHO (World health Organization) declared the corona virus outbreak 2019-2020 as public health emergency of international concern (PHEIC) on 30th January 2020 and a pandemic on 11th March 2020.
The virus was named corona virus owing to its appearance of the spikes on its surface that resemble a crown. ${ }^{1}$ The disease is highly infectious, it causes severe acute respiratory syndrome (SARS CoV-2), its main clinical symptoms may include fever, dry cough, shortness of breath, myalgia, sore throat, diarrhea, abdominal pain, loss of smell, and in severe conditions leading to viral pneumonia and multi-organ failure..$^{2-5}$

The COVID-19 pandemic has affected many countries all over the world. There are more than 81.9 million people 
infected and more than 1.8 million deaths due to COVID19 in the past few months from different countries as in official situation report of 1 January 2021 by the World Health Organization (WHO) ${ }^{3}$ In India, there are more than 2.5 lac active COVID19 cases and case fatality rate of COVID-19 is $1.45 \%$ as per Ministry of Health and Family Welfare (MoHFW) on 1 January 2021.

This virus spreads through respiratory droplets and by close contact from people to people. ${ }^{6}$ From the time of exposure to onset, the symptoms show between 2-14 days, with an average of 5 days. ${ }^{7,8}$ The standard test to be conducted for the detection of the virus is reverse transcription polymerase chain reaction (rRT-PCR) from a nasopharyngeal swab. ${ }^{9,10}$

Preventive steps are being taken to limit the spread of infection and impact of corona virus illness. Proper knowledge and practices about prevention strategies like frequent and thorough wearing mask outside home, hand washing with soap and water, not touching our face, eyes and nose, social distancing of 6 feets, avoiding large social lgatherings, and regularly cleaning frequently touched surfaces along with knowing when to contact doctor should be present in society. ${ }^{11}$

The battle against COVID-19 is still continuing in India. To guarantee the final success, people's adherence to preventive measures is necessary, which is mainly affected by their knowledge, attitudes, and practices (KAP) towards COVID-19. ${ }^{12,13}$ Previous evidence suggests that in case of infectious diseases, knowledge and attitudes towards the disease are associated with level of panic emotion among the population, which can further affect attempts to prevent the spread of the disease. ${ }^{14,15}$

By assessing public awareness and knowledge about the COVID-19, deeper insights into existing public perception and practices can be gained, thereby helping to identify factors that influence the public in adopting healthy practices and responsive behavior. ${ }^{16}$

Therefore, we conducted a survey to investigate the KAP towards COVID-19 among general population in northern India.

\section{METHODS}

\section{Study area}

The study areas were Delhi NCR cities Gurgaon, Rohtak and Rewari.

\section{Study design and population}

This cross-sectional study was conducted among the general population of northern India, from 22 August 2020, to 5 September 2020. During this survey, 109 persons were interviewed. Among these responses, 5 were incomplete or 4 did not give consent; therefore, our final sample size was of 100 participants. Distribution of participants by age, gender, education, occupation and income group was made. The number of participants in each of these groups was calculated along with their knowledge, attitude and practices.

\section{Data collection and management}

Given the social distancing (physical distancing) measures; data was collected telephonically, using a questionnaire. This study aimed to gather data from as diverse respondents as possible. The study participants were informed about the details of the study objectives and confidentiality at the beginning of the survey, and verbal informed consent was obtained from each participant. It was disclosed to all the participants that their identity would be kept confidential and the results would be used only for research purposes.

A structured questionnaire was used to collect the information. Total 30 questions were included in questionnaire, related to basic knowledge about the cause of disease, mode of transmission, high risk categories, symptoms of COVID19, preventive methods, attitude about various government implemented measures to tackle COVID 19 and practices used for prevention of the disease. The questionnaire was prepared from current interim guidelines and information provided by Ministry of Health and Family Welfare (MoHFW) and WHO.

\section{Data analysis and interpretation}

Data was entered into the computer with Statistical package for social sciences (SPSS) software and was analyzed using this software. Results are represented in the form of percentages and figures.

\section{RESULTS}

\section{Social and demographic characteristics}

The final sample consisted of 100 participants. Among this final sample, as shown in table 1, the average age was 33.0 years, $41 \%$ were women and $59 \%$ were men, $46 \%$ held a bachelor's degree or above, $89 \%$ were employed.

\section{Knowledge}

The majority of the participants $(88 \%)$ knew that virus is the cause of COVID-19 disease. $86 \%$ knew the name of causative organism of COVID-19. When asked about mode of spread, as shown in Figure 1b, 35\% had complete knowledge about all the modes of spread, $57 \%$ had partial knowledge out of which $37 \%$ knew about 2/3, $20 \%$ knew about $1 / 3$, and $8 \%$ had no idea about mode of transmission. As shown in Figure1a, 82\% opted for respiratory droplets (coughing, sneezing), $76 \%$ opted for touching and shaking hand with infected person, $37 \%$ opted for use of objects used by infected person, $5 \%$ opted for needle/blood and $8 \%$ had no idea about mode of transmission. 
Regarding symptoms of the disease, as shown in Figure 2, $38 \%$ answered all the options, $50 \%$ answered 2 or more options while $12 \%$ did not know any. $88 \%$ participants voted for fever, $62 \%$ for dry cough, $55 \%$ for sore throat, and $82 \%$ for difficulty in breathing.

Table 1: Social and demographic characteristics of the study participants.

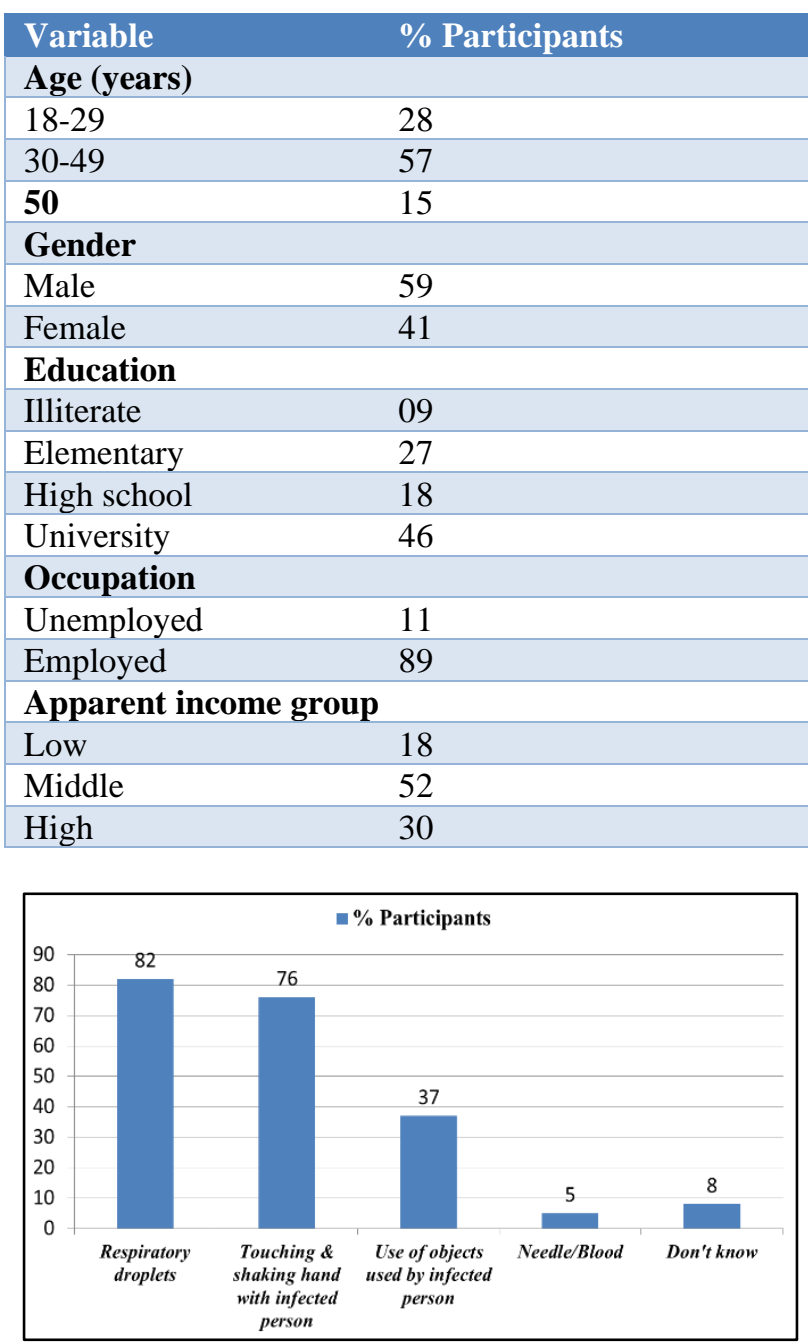

Figure 1a: Responses regarding mode of spread of infection.

$72 \%$ had complete knowledge about groups at higher risk of developing severe disease (i.e. elderly people, history of travelling to high risk area, comorbidities) while $16 \%$ had partial knowledge and $12 \%$ did not know any of the categories.

Knowledge regarding the prevention of the disease was as shown in Figure 3, such as $37 \%$ knew all the methods of prevention, $52 \%$ knew about some of them while $11 \%$ did not know any of them. Among them, $89 \%$ knew that COVID-19 can be prevented by social distancing and avoiding public transportation, furthermore $82 \%$ knew about washing hands regularly and $80 \%$ knew that wearing mask while leaving home is important for prevention while
$48 \%$ believed that taking antibiotics can prevent the disease which was not correct and $11 \%$ had no idea about method of prevention.

$62 \%$ were aware that hands should be scrubbed for a particular time interval (20-30 seconds), $69 \%$ believed that best way to wash hands for prevention for COVID-19 was only by washing hands with alcohol-based sanitizer but only $31 \%$ believed that the best way to wash hands is using running water and soap. They were guided also regarding suitable methods of hand washing.

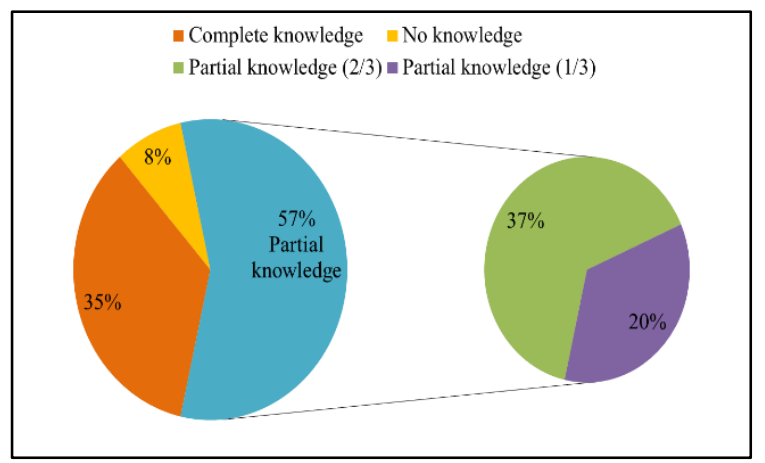

Figure 1b: Knowledge regarding mode of spread of infection.

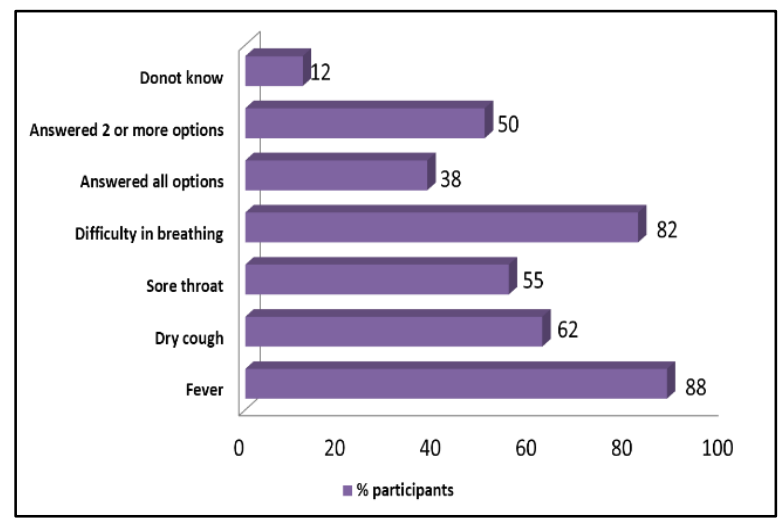

Figure 2: Knowledge regarding symptoms of COVID19.

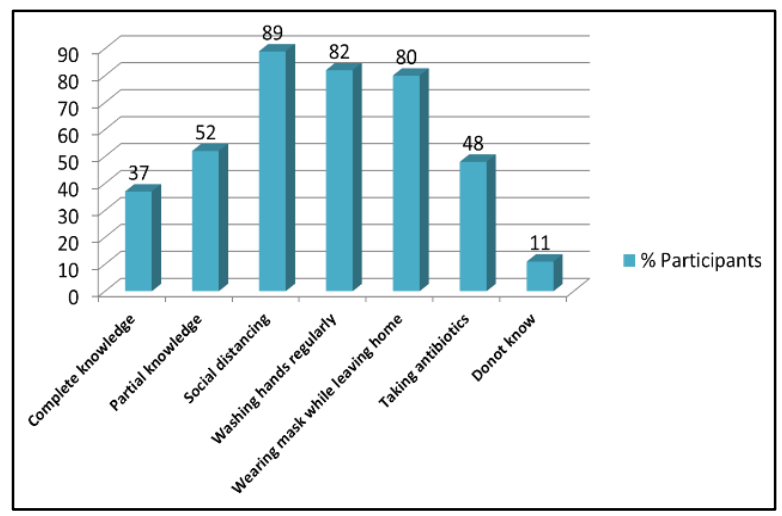

Figure 3: Responses regarding methods of prevention. 
$53 \%$ participants understood the term quarantine. Regarding vaccine for COVID-19, 58\% answered that no vaccine is approved for prevention till date while $14 \%$ thought vaccine is available, $28 \%$ had no idea. Furthermost, $80 \%$ participants answered that no approved drug is available for treatment, $8 \%$ believed availability of approved drug and $12 \%$ people had no idea regarding the mode of treatment. Most common source of information was TV $(89 \%)$ while other sources were posters $(33 \%)$, newspaper (24\%), you tube (18\%). $84 \%$ of the participants were aware about Aarogya setu app. $18 \%$ believed that every infected person develops severe disease. $62 \%$ people believed that all infected persons need treatment. $82 \%$ were aware that all people with fever, cough and breathing difficulty should seek medical attention. Only 54\% were aware that asymptomatic persons can transmit the disease.

\section{Attitude}

$72 \%$ had confidence that India can win the battle against COVID-19. High percentage of the participants $(88 \%)$ believed that we should avoid leaving our homes. In addition, $79 \%$ of the participants supported isolating serious patients in specialized hospitals by government. $83 \%$ believed that they should stay home if develop fever and cough. $88 \%$ were in favor of avoiding social gathering as well as public transport.

\section{Practice}

Under this heading we evaluate health-seeking behavioral intentions and prevention practices of the participants. $62 \%$ participants had not visited any crowded place and $78 \%$ wore masks when going out in recent days. There was still a good portion of the participants who had visited crowded places $(38 \%)$ and had not worn masks when leaving home (22\%) recently. $66 \%$ participants clean their hands often with soap and water or sanitizer, $60 \%$ avoid touching eyes, nose and mouth, $68 \%$ cover their nose and mouth while coughing/sneezing with tissue paper or bended elbow. Only $48 \%$ maintained 6 feet distance properly between them and with others who were coughing/ sneezing. $72 \%$ people washed vegetable and fruits bought from market.

\section{DISCUSSION}

COVID-19 is an infectious disease that poses a significant threat to public health. Because of the continuing threats imposed by COVID-19 and the absence of an effective and safe COVID-19 vaccine till now, preventive measures play a necessary role in reducing infection rates and controlling the spread of the disease. This indicates the necessity of public adherence to preventive and control measures, which is affected by their knowledge, attitudes, and practices. Thus, this study aimed to assess the KAP of the northern population of India, for the novel coronavirus disease 2019, COVID-19.

Our findings indicate that most study participants were knowledgeable in most of the areas about COVID-19 like mode of spread of the disease, symptoms, methods of prevention and when to seek medical attention. This finding is consistent with other studies that have shown satisfactory levels of knowledge, across the Indian population for COVID-19. ${ }^{17}$ In our study, the good rate of correct answers to knowledge-related questions among participants may be due to the characteristics of the sample, as $91 \%$ were literate, $89 \%$ were employed and $82 \%$ were from middle and high income group. It may also be due to the timing of survey after some time of declaration of pandemic. In that time, people may have gained awareness and knowledge about the disease and its transmission, via television and other media platforms.

Most of the participants in our study were aware of the clinical symptoms (88\% regarding fever and $82 \%$ regarding difficulty in breathing), and $80 \%$ knew that there is no clinically approved treatment for COVID-19 as of the date. In our study, knowledge level is good probably due to orientation by $\mathrm{TV}$, internet and social media.

In another study conducted by Joshi et al on similar topic COVID-19, knowledge and awareness among nursing students in Telangana, overall correct responses of knowledge and awareness was recorded as $75.58 \%$, this difference could be due to the reason that both studies were conducted at different time period. ${ }^{18}$

However, approximately half of the respondents in our study were unaware that COVID-19 could spread from asymptomatic person. It was also observed that $31 \%$ participants had little knowledge of best method to clean hands to prevent infection i.e. soap and running water. In a similar study done by Maheshwari et al among medical students of government medical college Uttarakhand, $88.1 \%$ participants responded that a person can transmit COVID-19 virus to others even when fever is not present. ${ }^{19}$ These findings highlight the need to continue to encourage and emphasize maintaining social distancing even if someone is asymptomatic and spreading awareness about best method of hand cleaning as a means of preventing the spread of the virus.

Concerning attitudes, participants showed a positive and optimistic attitude toward COVID-19. Approximately $72 \%$ were of the opinion that the Indian government will control the pandemic. In a similar study done by Maheshwari et al among medical students of government medical college Uttarakhand, $73.2 \%$ participants believed that COVID-19 virus finally will be successfully controlled. Our results regarding attitude are quite similar to this study. ${ }^{19}$

Nevertheless, our results show that the participants knowledge of COVID-19 does not translate into good and safe practices, which suggests that there are significant number of people are not very cautious. Only $48 \%$ of respondents maintain a 6 feet distance, $62 \%$ refrained from going in crowded places, $66 \%$ clean their hands regularly, $78 \%$ wore mask while leaving home. In a similar study done by Maheshwari et al19 among medical students of 
government medical college Uttarakhand, 98.3\% participants responded that they maintained social distancing, 98.6\% avoided unnecessary travel, 96.6\% washed their hands frequently while $91 \%$ wore mask often. This difference could be due to different population in both the studies as their study was done on medical students, on the other hand our study was conducted on general population.

Viral infections have been documented to be highly contagious among people in close proximity. ${ }^{20}$ Our findings suggest that greater emphasis should be placed on mass media to improve public knowledge on the COVID19 as TV was most common source of information (89\%).

It is important to note that there has been a great deal of efforts at all levels by the Government of India (GOI), including Aarogya setu app. The GOI has conducted an intensive awareness campaign, communicated via its website, television and various social media.

\section{CONCLUSION}

Knowledge and attitude in most of the areas were quite adequate but actual practices for preventing measures were lacking. So, more awareness programs and more such surveys regarding following the appropriate measures are need of the hour to prevent the spread of this highly communicable and deadly disease. The study participants were also guided regarding preventive measures and good practices relating to COVID-19 after collecting the data using a questionnaire.

\section{Recommendations}

Recommendations to reduce the risk of COVID-19: Persons above 65 years of age, persons with comorbidities, pregnant women, and children below the age of 10 years are advised to stay at home. Physical distancing of at least 6 feet to be followed as far as feasible. Use of face covers/masks while going outside. Practice frequent hand washing with soap (for at least 40-60 seconds) even when hands are not visibly dirty. Use of alcohol-based hand sanitizers (for at least 20 seconds) if soap and water not available. Cover mouth and nose while coughing/sneezing with a tissue /handkerchief / flexed elbow and dispose-off used tissues properly. Self-monitoring of health and reporting any illness at the earliest to state and district helpline. Install and use of Aarogya Setu App.

\section{Funding: No funding sources}

Conflict of interest: None declared

Ethical approval: The study was approved by the Institutional Ethics Committee

\section{REFERENCES}

1. Wang L, Wang Y, Ye D, Liu Q. Review of the 2019 novel coronavirus (SARS-CoV-2) based on current evidence. Int $\mathbf{J}$ Antimicrob Agents. 2020;55(6):105948.

2. Sugiyama K, Suto T, Amano Y. A new corona-like virus causing diarrhea in infant mice (DVIM): morphological and biological characteristics (author's transl). Uirusu. 1978;28:10-18.

3. Tsunoda A. Corona virus. Naika. 1970;26:435-40.

4. Cao J, Tu WJ, Cheng W, Yu L, Liu YK, Hu X, et al. Clinical Features and Short-term Outcomes of 102 Patients with Coronavirus Disease 2019 in Wuhan, China. Clin Infect Dis. 2020;71(15):748-55.

5. Nagashima K, Wege H, ter Meulen V. Early and late CNS-effects of corona virus infection in rats. Adv Exp Med Biol. 1978;100:395-409.

6. Wang D, Zhou M, Nie X, Qiu W, Yang M, Wang X, et al. Epidemiological characteristics and transmission model of Corona Virus Disease 2019 in China. J Infect. 2020;80(5):25-7.

7. Yang C, Ma QY, Zheng YH, Yang YX. Transmission routes of 2019-novel coronavirus (2019-nCoV). 2020;54:374-77.

8. Dietz L, Horve PF, Coil DA, Fretz M, Eisen JA, Van Den Wymelenberg K. 2019 Novel Coronavirus (COVID-19) Pandemic: Built Environment Considerations To Reduce Transmission. mSystems. Apr 2020;5(2):e00245-20.

9. Ieki R. Diagnostic tests: Corona virus. Nihon Rinsho. 2005;63(7):339-42.

10. Kuratsuji T, Kirikae T. Diagnostic tests: SARSCorona virus. Nihon Rinsho. 2005;63(7):343-45.

11. Harvard Health Publishing Coronavirus Resource Center. As coronavirus spreads, many questions and some answers. Available from:https://www.health.harvard.edu/diseasesandconditions/coronavirus-resource-cen. Last accessed on

12. Ajilore K, Atakiti I, Onyenankey K. College students' knowledge, attitudes and adherence to public service announcements on Ebola in Nigeria: Suggestions for improving future Ebola prevention education programmes. Health Education Journal. 2017;76:64860.

13. Tachfouti N, Slama K, Berraho M, Nejjari C. The impact of knowledge and attitudes on adherence to tuberculosis treatment: a case-control study in a Moroccan region. Pan Afr Med J. 2012;12:52.

14. Person B, Sy F, Holton K, Govert B, Liang A, National Center for Inectious Diseases SCOT. Fear and stigma: the epidemic within the SARS outbreak. Emerg Infect Dis. 2004; 10:358-63.

15. Tao N. An analysis on reasons of SARS-induced psychological panic among students. Journal of Anhui Institute of Education. 2003;21:78-9.

16. Podder D, Paul B, Dasgupta A, Bandyopadhyay L, Pal A, Roy S. Community perception and risk reduction practices toward malaria and dengue: a mixed method study in slums of Chetla, Kolkata. Ind J Public Health. 2019;63:178.

17. Pandey S, Gupta A. Bhansali R, Balhara S, Katira P and Fernandes G. Corona Virus (COVID-19) 
Awareness Assessment - A Survey Study Amongst the Indian Population. J Clin Med Res. 2020;2(4):1-10.

18. Joshi KP, Madhura L, Jamadar D. Int J Community Med Public Health. 2020;7(7):2518-21.

19. Maheshwari S, Gupta PK, Sinha R, Rawat P. Knowledge, attitude, and practice towards coronavirus disease 2019 (COVID-19) among medical students: A cross-sectional study. J Acute Dis. 2020;9(3):100-4.

20. CDC. Centers for Disease Control and Prevention: Coronavirus (COVID19) 2020. Available online at:
https://www.cdc.gov/coronavirus/2019-nCoV/ index.html. Accessed on $25^{\text {th }}$ December 2020.

Cite this article as: Amiya, Kaushal J. Knowledge, attitude, and practices towards COVID-19 among general population in northern India. Int J Basic Clin Pharmacol 2021;10:287-92. 